\title{
Piaget e as Teorias da Evolução Orgânica
}

\author{
Piaget and the Theories of Organic Evolution
}

\author{
Argus Vasconcelos de Almeida* \& Jorge Tarcísio da Rocha Falcão** \\ Universidade Federal de Pernambuco, Recife, Brasil
}

\begin{abstract}
Resumo
As teorias da evolução orgânica, principalmente a de Darwin, tiveram enorme impacto nas ciências humanas, notadamente na psicologia. Piaget importou da biologia diversas formulações teóricas que fundamentaram as suas teorias sobre o desenvolvimento ontogenético humano. A sua tese central estabelece a existência de uma correspondência de funções e isomorfismos parciais de estruturas entre a biologia evolutiva e as funções cognitivas dos sujeitos. Entretanto, suas idéias sobre a evolução dos seres vivos, com ênfase no papel do comportamento na evolução, pouca influência tiveram na biologia dominante de sua época. Não obstante, as teorias epigenéticas contemporâneas da evolução, em confronto teórico com o paradigma neodarwinista, reproduzem e atualizam as idéias piagetianas sobre a evolução e desenvolvimento dos seres vivos. Nesse sentido, defende-se aqui a idéia segundo a qual Piaget formula plataforma teórica que estabelece bases comuns para a psicogênese e a evolução orgânica.

Palavras-chave: Desenvolvimento e evolução; epigênese; psicogênese; teorias da evolução orgânica.
\end{abstract}

\begin{abstract}
Theories of organic evolution, mainly those proposed by Darwin, have strongly influenced human sciences in general, and psychology in particular. Piaget has brought from biology several theoretical proposals which gave support to his formulations concerning human ontogenetic development. The theoretical link between biological and psychological formulations was based on the proposition of correspondences and partial isomorphism between evolutionary biology and cognitive development. However, Piaget's ideas about phylogenetic evolution of live organisms have had little influence over current biology. Nevertheless, epigenetic contemporary theories of biological evolution make use of Piaget's propositions, in theoretical opposition to the neo-Darwinist views. Because of that, it is proposed in this paper the crucial contribution of Piaget in terms of the proposition of a common theoretical ground for psychogenesis and organic evolution.

Keywords: Development and evolution; epigenesis; psychogenesis; theories of organic evolution.
\end{abstract}

Darwin conclui seu livro "Origem das espécies" com a seguinte afirmação:

A psicologia será solidamente estabelecida sobre a base tão bem definida já por M. Herbert Spencer, isto é, sobre a aquisição necessariamente gradual de todas as faculdades e de todas as aptidões mentais, o que lançará uma viva luz sobre a origem do homem e sua história. (Darwin, 1859/1961, p. 488).

Ao propor tais idéias, Darwin antecipava a enorme repercussão da teoria da Evolução sobre as ciências humanas, particularmente, sobre a psicologia. Entretanto, a alusão a Spencer aponta para uma outra direção que não autoriza os atuais psicólogos evolucionários a usar tal citação para justificar o referencial teórico darwinista. Darwin, ao mencionar Spencer, referia-se às semelhanças de manifestações expressivas entre os animais e o homem, no que diz respeito às emoções básicas, conforme é descrito mais tar-

*Endereço para correspondência: Rua Joana Norberto Pessoa, 1051, Apto. 603, Casa Caiada, Olinda, PE, 53130-030. Tel. (081) 3432 1488.E-mail: argus@db.ufrpe.br

** Endereço para correspondência: Av. Odilon Gomes de Lima, 2001, Capim Macio, Natal, RN, 59078-400. E-mail: falcao.jorge@gmail.com de (1872) na obra "A expressão das emoções no homem e nos animais" (Darwin, 1872/2000). Nessa obra propõe-se que, nossas expressões emocionais compartilhariam aspectos herdados de antepassados primitivos comuns ao homem e a outros animais. Darwin referia-se também à obra de Herbert Spencer "Princípios de Psicologia", publicada em 1855, (isto é, antes da publicação da "Origem das espécies") e que segundo Darwin, tão bem estabeleceu as bases da psicologia. Vale a pena salientar que nesta e em obras posteriores (mesmo após a morte de Darwin) Spencer sustentar que a herança dos caracteres adquiridos desempenharia um papel mais significativo no processo evolutivo do que a seleção natural (Martins, 2004). Tal perspectiva levou Baldwin (1913/1999-2000) a propor que Spencer inicialmente trabalhou a sua teoria psicológica sob um referencial lamarckista, e somente depois a compatibilizou com a teoria da seleção natural de Darwin.

De acordo com Angell (1909) as idéias mais revolucionárias de Darwin sobre a "evolução mental" não apareceram até a publicação da "Origem do homem" em 1871. De uma forma geral pode-se atribuir a Darwin uma grande influência sobre mudanças contemporâneas ocorridas na psicologia funcional genética e na psicologia animal. Tal 
influência pode ser resumida em termos de três aspectos principais: (a) a doutrina da evolução do instinto; (b) a teorização acerca da evolução da mente animal, do mais primitivo ao mais complexo e (c) as proposições acerca das expressões da emoção em animais não-humanos e humanos.

Segundo Whitney (2002), Galton (primo de Darwin) descobriu que os traços psicológicos não eram menos herdáveis do que eram os traços físicos. Ele propôs o termo "eugenia" para a nova ciência da hereditariedade e da evolução humana. No começo do século XX muitos progressistas sociais eram eugenistas, e os fundadores intelectuais das ciências sociais e psicológicas eram completamente darwinistas. Como exemplo tem-se William James, considerado por muitos como o primeiro psicólogo da América, e G. Stanley Hall, fundador da Associação Psicológica Americana; estes dois personagens da história recente da psicologia contribuíram para a consideração da psicologia como um ramo das ciências naturais. O estudo da psicologia deveria contribuir para o fornecimento de subsídios em relação a dois aspectos centrais da evolução darwiniana: primeiramente o estudo de diferenças individuais herdáveis, e em segundo, o estudo da seleção natural como construto teórico explicativo dos instintos humanos e predisposições comportamentais herdadas. A orientação teórica principal na psicologia estadunidense do final do século XIX e início do século XX foi nomeada "funcionalismo", para enfatizar o estudo da "função", ou seja, como algum traço psicológico funcionou no esforço para a sobrevivência decorrente da seleção natural.

No início do século XX, John Watson surge como um dos defensores da eliminação da influência da hereditariedade darwiniana na psicologia. Em 1916, num trabalho intitulado "O lugar do reflexo condicionado na Psicologia" introduziu o reflexo condicionado, cujo estudo havia sido aprofundado pelos russos Pavlov e Bechterev, como base explicativa para o comportamento humano. Em sua perspectiva a aprendizagem condicionada era central, enquanto as influências herdadas no desenvolvimento eram simplesmente sem importância (Whitney, 2002).

Entrementes, no final dos anos 20 do século passado, um jovem biólogo suíço dá início a uma série de pesquisas de campo sobre caramujos aquáticos ocorrentes nos pântanos. Nessa época, mal poderia antever que suas pesquisas com esses pequenos organismos teriam tanta influência nas suas idéias sobre evolução e desenvolvimento dos seres humanos, oferecendo uma base teórico-reflexiva comum para a biologia e a psicologia.

\section{A Construção da Visão Evolutiva de Piaget}

Jean Piaget (1896-1980) interessou-se desde muito cedo por mecânica, fósseis e zoologia. Ao lado da formação científica em biologia, sentiu-se igualmente atraído pelo que chamou de "demônio da filosofia". Licenciou-se em 1915 em Ciências Naturais (Palangana, 1994).

De acordo com Palangana (1994), Piaget, biólogo por formação, ao se interessar pela filosofia tentou formular uma teoria que articulasse a questão da origem e desenvolvimento do conhecimento humano com a biologia.

Jean Piaget foi o propositor da Epistemologia Genética, cujas formulações teóricas foram desenvolvidas ao longo de décadas de trabalho empírico e reflexão iniciadas em Genebra no âmbito do "Institut Jean-Jacques Rousseau", e levadas posteriormente a seu ponto máximo de produtividade no "Centre Internationale d'Épistemologie Génétique". As formulações desenvolvidas por Piaget sofreram importantes influências de filósofos como Bérgson com a visão filosófica que elege o élan vital como um impulso emanado da vida e propiciador de transformação e mudança, ou seja, desenvolvimento. Outra referência importante foi Brentano, propositor de uma "psicologia do ato" fiel à metodologia observacional e fornecedora dos alicerces do método clínico. Já no campo da Biologia, cabe mencionar o aporte de Lamarck, através da ênfase no papel do ambiente para a evolução, bem como de Darwin, com a proposta de noções relacionadas à idéia de adaptação. Baldwin (1913/1999-2000), finalmente, foi responsável por contribuição decisiva no sentido da compreensão e explicação da gênese do pensamento, no âmbito da epistemologia genética ligada à evolução, para a qual a idéia de "seleção orgânica" teria importância central. Segundo observa Vonèche (1997), estas noções baldwinianas serviram a Piaget como fonte de subsídios no sentido de uma contraposição à idéia de acaso do neodarwinismo.

Sobre os seus pressupostos biológicos, escreve Piaget (1967/2000) que o estudo do desenvolvimento psicológico das funções cognitivas levanta continuamente questões biológicas relacionadas à embriogênese, bem como questões fundadas nas relações entre os organismos e o meio ambiente, principalmente no que tange às regulações daqueles por este (como será discutido mais adiante).

Para Casávola e Castorina (1988) existiria na teoria piagetiana uma continuidade entre os processos biológicos e cognoscitivos baseada em analogias funcionais. Escreve Palangana (1994) que dentre os aspectos que Piaget transfere da biologia para a psicogênese, pode ser destacado especialmente o ajustamento de antigas estruturas a novas funções e o desenvolvimento de novas estruturas para preencher funções antigas. Assim, a estrutura e adaptação encontram-se presentes na atividade mental, já que, para Piaget, a inteligência seria uma característica biológica do ser humano. É por intermédio do mecanismo de adaptação a novas e diferentes circunstâncias que as mudanças nas estruturas mentais ocorreriam. A função adaptativa compreenderia dois processos distintos e complementares: assimilação e acomodação. Segundo a autora, é este movimento em espiral de adaptação a novas circunstâncias, indo em direção a um estado superior e mais complexo de equilíbrio que Piaget denomina de equilibração majorante.

Sua hipótese central, desenvolvida principalmente nas obras "Biologie et connaissance" de 1967, sumarizada no segundo capítulo da obra "L'epistémolgie génétique" de 1970 e "Le comportament, moteur de l'évolution" de 1976, é, nas suas próprias palavras: 
A vida é essencialmente auto-regulação. A explicação dos mecanismos evolutivos, encerrada por muito tempo na alternativa sem saída entre o lamarckismo e o neodarwinismo clássico, parece encontrar seu caminho na direção de um tertium, que é cibernético e se orienta efetivamente no sentido da teoria da auto-regulação . . . Os processos cognoscitivos aparecem então simultaneamente como a resultante da auto-regulação orgânica, da qual refletem os mecanismos essenciais, e no âmbito das interações com o exterior, de tal maneira que acabam, no homem, por estendê-las ao universo inteiro. (Piaget, 1967/2000, p. 38).

Note-se que o confronto teórico entre as duas teorias da evolução se coloca entre o lamarckismo e o "neodarwinismo clássico" e não entre o lamarckismo e o darwinismo. Isto porque Piaget tinha plena consciência que os mecanismos evolutivos de Lamarck e Darwin tinham aproximações (teorias da pangênese, uso e desuso e herança dos caracteres adquiridos (Almeida \& Da Rocha Falcão, 2005). Para Piaget, portanto, haveria divergência entre o lamarckismo e o chamado "neodarwinismo clássico", fundado no mutacionismo (Vuyk, 1981a). Conforme propõe Weismann, a teoria mutacionista foi desenvolvida por Hugo de Vries numa fase de transição entre o darwinismo e o neodarwinismo, como uma teoria evolutiva antidarwinista, para depois ser remanejada teoricamente e incorporada ao programa neodarwinista. A partir dos anos 30 e 40 do século passado, a teoria evolutiva moderna tem a sua construção na chamada Síntese Evolutiva ou Síntese Moderna que moldou as contribuições das áreas da genética, sistemática e paleontologia em uma nova teoria neodarwinista, que teve o papel de reconciliar a teoria de Darwin com a genética.

Ora, o deslocamento promovido por Piaget, não coloca em divergência Darwin e Lamarck, e sim Lamarck e o mutacionismo. Poucas vezes citado, quando comparado com Lamarck, Darwin é uma referência que permanece num plano secundário na obra de Piaget.

\section{As Pesquisas Biológicas de Piaget e sua Formulação de Uma Teoria da Evolução}

A teoria da evolução de Piaget é fundamentalmente baseada no construto teórico de fenocópia. Este termo foi cunhado inicialmente por R. Goldshimidt e ressignificado por Piaget, que vai defini-lo nos seguintes termos: "um novo caráter apresenta-se sob uma forma fenotípica, depois, após uma fase em que se encontra uma mistura de fenótipos e de genótipos nascentes, o mesmo caráter, ou pelo menos a sua 'cópia', torna-se propriedade de um genótipo estável” (Piaget, 1976/1977, p. 92). Trata-se, portanto da substituição de um fenótipo inicial por um subseqüente genótipo apresentando as mesmas características.

A hipótese sobre fenocópia de Piaget foi inspirada pelas suas pesquisas realizadas em 1929 com caramujos aquáticos de pântanos (Limnaea stagnalis L.). O dado essencial é que L. stignalis, que comumente possui uma concha de forma alongada, passa a adquirir uma forma de concha curta (contraída) com abertura alargada em águas turbulentas com fortes ventos e ondas (formas lacustris e bodamica). A forma encurtada da concha se deve aos movimentos do animal, quando se fixa fortemente contra as pedras na turbulência das águas. Essa diferença morfológica é consequiência do seu comportamento adaptativo, tendo em vista as peculiaridades de seu ambiente. As formas contraídas são hereditárias, ou seja, mesmo quando recolocadas no ambiente original pantanoso, os caramujos mantêm as características da forma alterada das conchas. Há, portanto, de acordo com Piaget (1967/2000, p. 343) uma "herança do adquirido", interpretada pelo autor como um caso de assimilação genética no sentido de Waddington, isto é, da fixação hereditária de uma variação fenotípica inicialmente não fixada.

Entre as pesquisas realizadas por Piaget com vegetais nos anos 60, destacam-se as empreendidas com um grupo de plantas carnosas (Crassulaceae) do gênero Sedum, concebidas pelo autor como um exemplo de antecipação morfogenética entre os vegetais (Piaget, 1967/2000). Tais plantas se caracterizam pelo freqüente destacamento de ramos dando origem a novos indivíduos. Estes ramos caem ao solo e logo emitem raízes. A queda dos ramos é muito variável de uma espécie para outra. Nas espécies em que a queda é sistemática, ela parece preparada por um dispositivo morfológico de uma ranhura circular no ponto de inserção do ramo, acompanhada de uma constrição que facilita o destacamento. Tem-se aqui, portanto, uma antecipação morfogenética da queda do ramo, em interação com delicados fatores do ambiente, tais como gotas de chuva ou a passagem de um inseto.

$\mathrm{O}$ autor interpreta este caso como um processo reacional e fenotípico, caracterizado pelas seguintes etapas: (a) crescimento de um ramo; (b) estreitamento de sua base; (c) destacamento e queda no solo; (d) crescimento de raízes adventícias; (e) independência nutricional. $\mathrm{O}$ encadeamento das etapas deste processo mantém relação com as etapas precedentes que a reforçam, transformando um simples encadeamento linear em um sistema de alças, como uma espécie de esquema antecipador.

Com as mesmas plantas em obra posterior (Piaget, 1976/ 1977), Piaget desenvolve a sua idéia de compensações: Sedum sediforme que é normalmente esbranquiçado ao sol nas regiões mediterrâneas, possui formas mais clorofiladas quando cultivado à sombra ou submetido a contextos climáticos desfavoráveis. $\mathrm{O}$ autor interpreta que não é a falta de luz que os torna mais verdes, mas sim uma reação compensadora a essa situação. Piaget assinala que encontrou no vegetal as mesmas fenocópias encontradas em animais (moluscos).

Escreve Vuyk (1981b) que a teoria das fenocópias e o seu papel na evolução das formulações psicogenéticas de Piaget não teve a mínima repercussão entre os biólogos, os quais talvez não a tenham levado a sério devido a seu caráter especulativo. A exceção a tal indiferença entre os biólogos é representada por uma referência de Waddington publicada em 1973, onde o mesmo, referindo-se às propostas piagetianas referentes às fenocópias, se diz não-con- 
vencido de que as mudanças do caramujo dos pântanos tenham sido provocadas por assimilação genética e não por seleção natural. Esta crítica de Waddington, cujas teorias cibernéticas têm papel de relevo na constituição da base teórica de J. Piaget, devem ter calado fundo neste. Tanto que, em trabalho posterior (Piaget, 1976/1977), reelabora suas interpretações sobre a sua pesquisa com moluscos e critica Waddington por sua visão selecionista.

Entre as críticas à teoria piagetiana elencadas por Vuyk (1981a), destaca-se a de Rotman (1975), o qual enfatiza o conflito entre o modelo evolucionista ramificado de avanço cognitivo e a descrição linear do desenvolvimento por estágios. Outro ponto crítico focal destacado por Rotman (1975) citado por Vuyk (1981a) é a visão do desenvolvimento de Piaget, seja evolucionário ou ontogenético, como muito individualizado, a ponto de comparar estruturas de um indivíduo de uma espécie com indivíduos de outras espécies. Finalmente, considera que a teoria da evolução piagetiana é muito devedora de certas visões progressistas dos séculos XVIII e XIX, e incapaz de promover qualquer abalo no paradigma neodarwinista.

A grande obra de Piaget "Biologia e conhecimento" (Piaget, 1967/2000) têm seus fundamentos teóricos em biologia evolucionária, principalmente nas teorias cibernéticas de auto-organização do geneticista, paleontologista e embriologista Conrad Hal Waddington (1905-1975), que apesar de considerar-se um neodarwinista convicto, ocupa uma posição marginal (ou "alternativa") entre os teóricos formuladores do núcleo firme do programa de pesquisas neodarwinista. Suas idéias sobre assimilação genética, epigênese, homeorrese e créodos (Waddington, 1977) são consideradas por neodarwinistas ortodoxos como uma espécie de neolamarckismo.

Suas teorias sobre evolução orgânica são consideradas por Piaget (1967/2000) como um tertium entre o lamarckismo e o neodarwinismo clássico (mutacionismo).

Para Piaget, Waddington:

... é o primeiro a apresentar uma síntese propriamente dita, distinguindo no seio do sistema evolutivo quatro grandes subsistemas, tendo cada um suas próprias regulações, mas necessariamente ligados entre si por um conjunto de circuitos cibernéticos: 1) o sistema genético; 2) o sistema epigenético; 3) a exploração do meio; e 4) as ações da seleção natural . . . enquanto o lamarckismo via no germe um instrumento de simples registro das modificações somáticas, tendo por finalidade a transmissão hereditária, e o mutacionismo considerava este genoma como a única fonte de preformação ou das variações aleatórias, Waddington, depois de Dobzhanky, concebe-o enfim como um sistema ativo de 'respostas' e de reorganizações, que fazem frente ao meio sem simplesmente sofrer a influência dele, mas utilizando as informações dele provenientes, em lugar de ignorá-lo ou de impor-lhe seu programa. Tal é a novidade que representa este tertium ou a superação das teses até agora antitéticas. E é por isto que se pode agora considerar que as três correntes dominantes nas teorias da evolução são o lamarckismo e o neodarwinismo e as concepções nascentes resultantes da cibernética. (Piaget, 1967/2000, p. 142-143).

\section{Desdobramentos do Pensamento Piagetiano na Biologia Moderna}

Atuais pesquisadores em biologia evolutiva, comportamento evolutivo e biologia do desenvolvimento, tais como Dopazo e Perazzo (2001, 2002), Gilbert (2003) e Lewontin (1998), sugerem que os autores referenciados por Piaget, na formulação da sua teoria evolutiva, compartilham a idéia de que o ambiente tem um papel importante na evolução orgânica, de que os organismos vivos constituem-se em sistemas abertos e de que mecanismos cibernéticos estão envolvidos nos processos evolutivos. Entretanto, a importante contribuição de Piaget no campo da biologia evolutiva foi majoritariamente ignorada pelo establishment biológico da época.

Na compreensão de Piaget (1976/1977, 1970/2002) os mecanismos evolutivos não poderiam deixar de considerar o meio interno do organismo e as modificações que aí se produzem sob a influência de novos fenótipos. Mesmo que as mutações surjam neste contexto de natureza aleatória, a seleção do meio interno obedece a um mecanismo adaptativo muito mais preciso que a seleção natural, tendo em vista as correções contínuas das regulações epigenéticas. Pois, contrariamente às simples ações externas do tipo lamarckiano ou seleção externa do tipo darwiniano, todo esse mecanismo baseia-se na necessidade de reconstruções endógenas.

Em resumo, ou bem o acaso e a seleção são suficientes para todo o processo, ou o comportamento é o principal motor da evolução. Isto quer dizer que, ou existe um enorme desperdício do tipo ensaio-erro antes de qualquer solução, ou, conforme preconiza Piaget, existe um mecanismo dotado de uma lógica interna ligado à organização e autoregulação dos seres vivos (daí a sua profunda divergência com as idéias de Monod).

Para Piaget a idéia de assimilação genética de Waddington, é "o processo segundo o qual um caráter fenotípico, produzido inicialmente em resposta a uma influência do meio, se conserva, graças a uma seleção feita pelo genótipo, mesmo na ausência das condições exteriores que foram necessárias para a sua formação". Sua teoria evolutiva tem significativas aproximações com teorias biológicas atuais que estão questionando o modelo evolucionário neodarwinista. Dentre tais propostas contemporâneas destaca-se a idéia de "clausura operacional" de Maturana e Varela (2003), no contexto da qual estes teóricos concebem os organismos como sistemas abertos até um certo ponto, devendo-se considerar a relação dialética entre esta abertura e o seu fecho funcional em termos de ciclos, nos quais a identidade dos organismos está especificada por uma rede de processos dinâmicos fechados enquanto operam.

Sobre o papel do ambiente na evolução suas idéias tem uma grande aproximação com as de Lewontin (1998) quan- 
do este propõe que os organismos são construtores de seus próprios ambientes.

Numa crítica recentemente publicada, escreve Eichler (2006) com razão, que os biólogos não conhecem a biologia de Piaget (talvez pelas razões aludidas mais acima, relacionadas ao caráter especulativo de suas proposições), apesar do mesmo ter seguidamente enfatizado a importância da biologia e da filosofia para a construção de sua teoria. Uma vez que o número de textos de Piaget que apresentam sua biologia é considerável (mais de 42 artigos e 3 livros (cf. Eichler, 2006), a relativa marginalidade dessa parte de sua obra não pode ser atribuída a desconhecimento e/ou falta de textos de referência disponíveis. Segundo o autor, isto estaria justificado pela fraca difusão dos seus trabalhos biológicos, bases experimentais e técnicas fracas, com referência quase nula a bibliografia especializada.

Dessa forma, seus construtos teóricos explicativos da ontogênese e filogênese seriam difíceis de integrar na perspectiva da teoria sintética da evolução, cujo caráter simplista e reducionista Piaget denunciava. Finalmente, o próprio conteúdo e a retórica de Piaget são, de uma certa maneira, próximos do discurso filosófico. Uma vez que lhe faltara tempo suficiente consagrado à experimentação, ele construiu uma biologia racional que foi elaborada sobre poucas observações sistemáticas, a partir fundamentalmente de uma leitura crítica das teorias antigas e contemporâneas.

A finalidade da sua pesquisa biológica foi centrada sobre os dois mais importantes eixos da biologia, a ontogênese dos indivíduos e a evolução das espécies. Esses temas conduzem e unificam o seu projeto de pesquisa, no qual o objetivo central é compreender a significação das interações entre o organismo e o meio, na sua dimensão evolutiva. Essas interações foram vistas como essenciais tanto na formação das raças e variedades, como na formação das novas espécies.

Para Eichler (2006) Piaget concebia os organismos como sistemas dinâmicos, construtivos e auto-reguladores. Assim, a manifestação fundamental da atividade regulatória é a construção, pois, sistemas regulatórios constroem a si mesmos e também ao ambiente em sua volta. É o organismo que ativamente constrói uma estrutura operacional interna em sua busca do equilíbrio através de uma homeostase regulatória. É essa estrutura que codifica a informação ambiental em virtude do papel seletivo do ambiente em sua gênese, assim o conhecimento surge como um subproduto da atividade. Portanto, a atividade construtiva seria o foco distintivo tanto da psicologia quanto da biologia de Piaget. Isso explicaria o seu afastamento teórico do neodarwinismo ortodoxo.

Para Buscaglia (1985) citado por Eichler (2006), a biologia piagetiana poderia ser resumida em termos dos seguintes pontos: (a) Oposição à idéia de uma seleção natural passiva, do tipo neodarwinista; (b) Importância atribuída à intervenção da atividade individual, e por conseqüência à construção das vias possíveis da evolução, tendo em vista que os indivíduos são os determinantes da direção tomada, cujos limites determinam a seleção; (c) Elaboração de um modelo interacionista e epigenista do desenvolvimento ontogenético e filogenético; (d) Concepção do organismo como entidade autoregulada.

\section{A Epigênese Como Base Unificadora da Biologia e Psicologia em Piaget}

O paradigma epigenético que abrange a psicologia piagetiana e a biologia pode ser caracterizado pelos seguintes aspectos: (a) o desenvolvimento ocorre por epigênese, processo em que a experiência ambiental dos organismos entra como influência formativa necessária, não ocorrendo nenhuma preformação ou predeterminação dos genes; (b) as mudanças evolucionárias são iniciadas por mudanças desenvolvimentais; (c) estas mudanças desenvolvimentais não são arbitrárias, sendo determinadas pela dinâmica do próprio sistema epigenético; (d) as mudanças desenvolvimentais podem ser assimiladas pelo novo sistema organismo/ambiente como um todo, ajustando os seus parâmetros para uma futura evolução; (e) a epigênese atua na mediação entre os níveis biológico e psicossocial, servindo para integrar os dois níveis em um todo estrutural e funcional; (f) o desenvolvimento e a evolução são processos contínuos, no âmbito dos quais o organismo participa ativamente em dar forma à sua própria história desenvolvimental e evolucionária.

Tanto a teoria da evolução e do desenvolvimento de Piaget como as modernas teorias epigenéticas da evolução são tributárias da herança da teoria epigenética formulada por Waddington. Tal teoria parte da noção de epigênese, referente à influência do ambiente na expressão do código genético. A epigênese é correntemente compreendida como o processo de transformação de uma célula primordial, mediante sucessiva formação e adição de novas partes que não existiam previamente no ovo.

Para Ho (1998) existem diferentes teorias epigenéticas da evolução, algumas anteriores à síntese darwiniana. Um ponto comum a todas as teorias epigenéticas é a idéia da flexibilidade no desenvolvimento de todos os organismos. Em particular, observou-se que as modificações artificiais (induzidas) no desenvolvimento se assemelham freqüentemente (fenocópias) àquelas existentes naturalmente em raças geográficas relacionadas ou em espécies.

Nesta perspectiva, parece razoável supor que as novidades evolutivas se manifestam primeiramente como modificações desenvolvimentais que se tornaram de algum modo estavelmente hereditárias (ou não, conforme as circunstâncias) em gerações subseqüentes. O organismo experimentaria seu ambiente em um processo interativo contínuo, ajustando-se e mudando, deixando impressões no seu sistema epigenético, em seu genoma bem como no ambiente, sendo tais impressões passadas às gerações subseqüentes. Assim, não haveria nenhuma separação entre o desenvolvimento e a evolução. Dessa maneira, o organismo participaria ativamente do processo do seu próprio desenvolvimento, bem como da evolução de sua comunidade ecológica.

Para a mesma autora acima mencionada (Ho, 1998), quando a abordagem epigenética reafirma a natureza 
holística fundamental da vida não pode se basear em nenhuma justificação à idéia de um mecanicismo simplista dos efeitos arbitrários do uso e desuso ou da herança de caracteres adquiridos. Os organismos são considerados como complexos sistemas dinâmicos não-lineares, e como tais, possuem áreas de estabilidade e de instabilidade que lhes permitem manter a homeostase adaptando-se a mudanças.

Para Piaget, a adaptação à mudança comporta simultaneamente manutenção de uma estrutura prévia e alteração da mesma, ou seja, não haveria assimilação sem acomodação, nem o oposto. Nesse sentido, não faz sentido em falar de não-mudança em organismos tão dinâmicos: há sempre mudança, mas há sempre manutenção de uma estrutura invariante, num processo verdadeiramente dialético - apesar de muitos críticos considerarem que não há dialética no pensamento piagetiano...

Assim, a dinâmica do processo desenvolvimental fornece a chave para a hereditariedade e à evolução, ao determinar os tipos de mudanças que podem ocorrer, sua resistência a determinadas perturbações e sua suscetibilidade a outras.

Segundo Ho (1998) a teoria de Darwin comporta perspectiva acerca de um processo de seleção natural que envolve uma separação entre o organismo e seu ambiente. Segundo a autora, o organismo é fechado conceitualmente fora de sua experiência, conduzindo logicamente à barreira e ao dogma central de Weismann do paradigma genético, que é reducionista na intenção e na realidade. A teoria de Lamarck, por outro lado, funda-se sobre processos de transformação decorrentes da própria experiência do organismo no ambiente. Nesse sentido, tal teoria requer uma concepção do organismo como aberto ao ambiente e convida-nos a examinar a dinâmica da transformação, bem como os mecanismos por meio da qual a transformação pode ser “internalizada" (Ho, 1998).

De um ponto de vista teórico mais abrangente, Etxeberria e Umerez (2006) denominam de organicismo as posições teóricas que tentam superar a dicotomia entre o vitalismo e o mecanicismo. Confrontando-se tanto com um como com outro, o organicismo concorda com o primeiro em um certo holismo, que o leva a enfatizar a importância de levar-se em conta o conjunto do sistema, o todo, e a necessidade de diferentes níveis de explicação na organização dos seres vivos, porém compartilhando com o segundo a crença de que os processos vivos devem ser objeto de explicações materiais. $\mathrm{O}$ organicismo considera que o elemento fundamental da biologia é o organismo e trata de nele centrar as explicações dos processos vitais.

Para estes mesmos autores o conceito de "organismo" foi introduzido por Stahl no início do século XVIII em oposição ao mecanicismo então vigente e em referência ao conceito aristotélico de organon, proposto como explicação das funções do todo e das partes corporais. Etxeberria e Umerez (2006) chamam a atenção para o fato de que o termo organismo, em sua origem, não foi proposto como um mero sinônimo de ser vivo, pois fora cunhado para constituir algum tipo de teoria ou uma descrição definida do mesmo. O conceito de organismo apresenta, portanto descontinuidade histórica em relação ao mecanicismo, originando-se em reação a este e precisamente para ressaltar características não mecânicas dos seres vivos.

Assim, Etxeberria e Umerez (2006) consideram que todas as teorias epigenéticas da evolução, inclusive a de Piaget, fazem parte da perspectiva organicista e assim devem ser consideradas.

Já Azkonobieta (2005) estuda o problema da mudança evolutiva sob uma perspectiva centrada na organização, isto é, na biologia evolutiva do desenvolvimento (EvoDevo). Essa perspectiva supõe que deve haver uma mudança na percepção do processo evolutivo, já que este proporciona um estudo combinado da evolução e desenvolvimento orgânico, quer dizer, não só estuda como evoluem os sistemas de desenvolvimento, mas trata também de entender como o desenvolvimento afeta a dinâmica evolutiva. Esta última circunstância é especialmente relevante, já que se os mecanismos da evolução são essenciais para entender o desenvolvimento, e os mecanismos de desenvolvimento são essenciais para entender a evolução. Nessa ordem de idéias, a própria evolução há de refletir em si mesma certas propriedades do ser vivo.

No paradigma neodarwinista o poder causal da seleção natural como produtora de organização foi superdimensionado, em detrimento das propriedades inerentemente auto-organizativas da vida, que não foram consideradas como fatores relevantes para entender a evolução, muito ao contrário: a evolução chegou a ser interpretada como um processo impeditivo de tais peculiaridades individuais, o que gerou uma visão reducionista tanto da evolução como do organismo.

Para Azkonobieta (2005) pode-se constatar a existência de duas formas fundamentais de entender a vida no contexto da biologia atual: uma baseada em seu aspecto evolutivo e outra em seu aspecto organizativo, que em princípio não são facilmente integráveis (Azkonobieta, 2005). A visão externalista tenta compreender os sistemas vivos como produtos de um processo histórico adaptativo que pode interpretar-se como a mudança das freqüências genéticas das populações em função das pressões seletivas externas do meio. Para tal perspectiva, a vida seria vista como extremamente maleável frente às pressões adaptativas do meio, cabendo à evolução dotá-la de suas propriedades essenciais. A visão internalista, por sua vez, considera a compreensão da organização biológica como uma condição prévia e necessária para entender a evolução, e mais, tende a tratar a evolução como um fator secundário, não essencial à vida. A visão internalista provém de uma longa tradição biológica mais próxima a disciplinas como a biologia do desenvolvimento, a fisiologia e a biologia teórica. A evolução, nesse ponto de vista, mais que um mecanismo gerador de ordem, se interpreta como um processo dinâmico, orgânico, que emerge da organização biológica. A seleção natural, nesse ponto de vista, não tem propriedades gerativas, não é um mecanismo que produz organização, já que a seleção atua sobre uma variabilidade previamente organizada que demanda uma explicação. Por isso a sele- 
ção se interpreta mais como efeito do que como uma causa das propriedades organísmicas, e não é considerada como indispensável para entender a vida.

Uma das formas na qual se pode promover a integração da visão externalista e a internalista parte do conceito de auto-organização, isto é, o aparecimento espontâneo de padrões ordenados, organização por interação recorrente e não linear entre os componentes de um sistema. A sua universalidade a faz aplicável a uma grande quantidade de fenômenos biológicos e tem chegado a oferecer-se como uma alternativa a seleção natural, como princípio gerador de ordem na evolução.

\section{Considerações Finais}

Em toda a sua obra Jean Piaget sustenta a tese central de que existe uma correspondência de funções e isomorfismos parciais de estruturas entre a biologia evolutiva e o desenvolvimento das funções cognitivas dos sujeitos. A autoregulação cognitiva utiliza os mesmos sistemas gerais de auto-regulação orgânica, encontradas em todas as escalas genéticas, morfogenéticas, fisiológicas e nervosas e vai adaptá-las aos novos dados das trocas com o meio no âmbito do comportamento. Assim, para Piaget, as estruturas operatórias da inteligência são sistemas de transformações que conservam uma totalidade invariante, como os próprios organismos vivos. Esta conservação do todo através das transformações, supõe uma regulação, com reversibilidade de operações em forma de alças ou "feedbacks" que permitem remontar o curso das transformações (Piaget, 1967/2000).

Piaget concebe o comportamento como um conjunto de ações que os organismos exercem sobre o meio para modificarem seus estados ou para transformarem a sua própria situação em relação ao meio exterior. O comportamento, escreve ainda Piaget, tende para interiorizações representativas em que as ações se prolongam e são abstraídas em operações mentais. Mais ainda, o comportamento é constituído por ações de natureza teleonômica, tendo como objetivo utilizar ou transformar o meio e também conservar ou aumentar os poderes que os organismos exercem sobre esse meio (Piaget, 1976/1977).

Tendo por hipótese central que as adaptações desenvolvimentais são o motor da Evolução, Piaget (1970/ 2002) descarta as duas soluções extremas do lamarckismo, para o qual tais adaptações seriam o único fator, e do neodarwinismo, que não levanta este problema, baseandose em variações aleatórias do "pool" genético que têm valor adaptativo depois de passar pela seleção natural. Entre os dois extremos Piaget procura um tertium, desta vez baseado na reconhecida contribuição teórica de Baldwin, com a sua teoria da seleção orgânica; nas contribuições de Waddington, com a hipótese da assimilação genética; nas contribuições do biólogo austríaco Paul Alfred Weiss (18981989) com a idéia de dinâmica global. Como contribuições teóricas secundárias, Piaget incorpora (ou retém, nas suas palavras) as idéias sistêmicas de Bertalanffy (1982), as do biólogo evolutivo soviético Ivan Schmalhausen e, finalmente, na sua teoria evolutiva baseada na idéia de fenocópia.

Conforme discutido anteriormente, o aspecto teórico crucial que une as perspectivas de Piaget e pesquisadores atuais em biologia evolutiva é a proposição tríplice segundo a qual: (a) o ambiente tem um papel importante na evolução orgânica; (b) os organismos vivos constituem-se em sistemas abertos, e (c) mecanismos cibernéticos estão envolvidos nos processos evolutivos.

Finalmente, se a importante contribuição de Piaget no campo da biologia evolutiva continua a ser ignorada por parcelas do paradigma teórico dominante na biologia, suas idéias têm conexão com formulações contemporâneas extremamente relevantes na reflexão transdisciplinar que abarca questões que vão da ontogênese à filogênese, da biologia evolutiva à epistemologia genética, psicologia da aprendizagem e do desenvolvimento.

\section{Referências}

Almeida, A. V., \& Da Rocha Falcão, J. T. (2005). A estrutura histórico-conceitual dos programas de pesquisa de Darwin e Lamarck e sua transposição para o ambiente escolar. Ciência \& Educação, 1(11), 17-32.

Angell, J. R. (1909). The influence of Darwin on Psychology. Psychological Review, 16, 152-169.

Azkonobieta, T. G. (2005). Evolución, desarrollo y (auto)organización. Um estúdio sobre los princípios filosóficos de la evo-devo. Tesis Doctoral Inédita, Universidad del Pais Vasco, San Sebastián, España.

Baldwin, J. M. (1999-2000). Scientific Psychology in the nineteenth century. II, Special line of work. In J. M. Baldwin, History of Psychology: A sketch and interpretation. London: Watts. (Original publicado em 1913). Retrieved from http:// psychclassics.yorku.ca/Baldwin/History/

Bertalanffy, L. (1982). Perspectivas en la teoria general de sistemas (2. ed.). Madrid, España: Alianza.

Casávola, H. M., \& Castorina, J. A. (1988). Comentários sobre a doutrina biológica piagetiana. In J. A. Castorina, Psicologia genética: Aspectos metodológicos e implicações pedagógicas (pp. 123-130). Porto Alegre, RS: Artes Médicas.

Darwin, C. (1961). Origem das espécies. Porto, Portugal: Lello \& Irmão. (Original publicado em 1859)

Darwin, C. (2000). A expressão das emoções no homem e nos animais (2. ed.). São Paulo, SP: Companhia das Letras. (Original publicado em 1872)

Dopazo, H. J., \& Perazzo, R. P. J. (2001). Aprendizaje y evolución: adaptación acelerada por efecto Baldwin. Ciencia $e$ Investigación, 53(3), 3-8,

Dopazo, H. J., \& Perazzo, R. P. J. (2002), Mutual influence of learning and evolution. Complexity International, 9, Article dopazo01. Retrieved from http://www.complexity.org.au/ci/ vol09/dopazo01/dopazo01.pdf

Eichler, M. L. (2006). O programa adaptacionista em Psicologia e a teoria da evolução das espécies. Ciências \& Cognição, 7, 46-67.

Etxeberria, A., \& Umerez, J. (2006). Organismo y organización en la biología teórica ¿Vuelta al organicismo 50 años después? In A. Ambrogi (Ed.), Medio siglo de doble hélice. Palma de Mallorca, España: Edicions Universitat de les Illes Balears.

Gilbert, S. F. (2003). The morphogenesis of evolutionary developmental biology. International Journal of Developmental Biology, 47, 467-477. 
Ho, M. W. (1998). Evolution. In G. Greenberg \& M. M. Haraway (Eds.), Comparative Psychology: A handbook (pp. 107-119). New York: Garland.

Lewontin, R. (1998). A tripla hélice: Gene, organismos e ambiente. São Paulo, SP: Companhia das Letras.

Martins, L. A. C. P. (2004). Herbert Spencer e o neolamarckismo: Um estudo de caso. In R. A. Martins, L. A. C. P. Martins, C. C. Silva, \& J. M. H. Ferreira (Eds.), Filosofia e história da ciência no Cone Sul: III Encontro (pp. 281-289). Campinas, SP: AFHIC.

Maturana, H. R., \& Varela, F. J. (2003). A árvore do conhecimento: As bases biológicas da compreensão humana (3. ed.). São Paulo, SP: Palas Athena.

Palangana, I. C. (1994). Desenvolvimento \& Aprendizagem em Piaget e Vygotsky (a relevância do social). São Paulo, SP: Plexus.

Piaget, J. (1977). Comportamento motriz da evolução. Porto, Portugal: Res. (Original publicado em 1976)

Piaget, J. (2000). Biologia e conhecimento: Ensaio sobre as relações entre as regulações orgânicas e os processos cognoscitivos (3. ed.). Petrópolis, RJ: Vozes. (Original publicado em 1967)

Piaget, J. (2002). Epistemologia genética (2. ed.). São Paulo, SP: Martins Fontes. (Original publicado em 1970)

Vonèche, J. (1997). A origem das idéias de Piaget sobre gênese e desenvolvimento. In L. Banks-Leite (Ed.), Percursos piagetianos (pp. 21-34) São Paulo, SP: Cortez.

Vuyk, R. (1981a). Biology and knowledge. In R. Vuyk, Overview and critique of Piaget's genetic epistemology: Vol. 2 (pp. 475487). London: Academic Press.

Vuyk, R. (1981b). Organic and cognitive regulations. In R. Vuyk, Overview and critique of Piaget's genetic epistemology: Vol. 1 (pp. 233-264). London: Academic Press.

Waddington, C. H. (1977). Tools for thought. London: Paladin. Whitney, G. (2002). Subversion of science: How Psychology lost Darwin. The Journal for Historical Review, 21(2), 20. 